\title{
Status, Vision, and Challenges of an Intelligent Distributed Engine Control Architecture
}

\section{ABSTRACT}

A Distributed Engine Control Working Group (DECWG) consisting of the Department of Defense (DoD), the National Aeronautics and Space Administration (NASA) - Glenn Research Center (GRC) and industry has been formed to examine the current and future requirements of propulsion engine systems. The scope of this study will include an assessment of the paradigm shift from centralized engine control architecture to an architecture based on distributed control utilizing open system standards. Included will be a description of the work begun in the 1990's, which continues today, followed by the identification of the remaining technical challenges which present barriers to on-engine distributed control. 


\section{Status, Vision, and Challenges of an I ntelligent Distributed Engine Control Architecture}

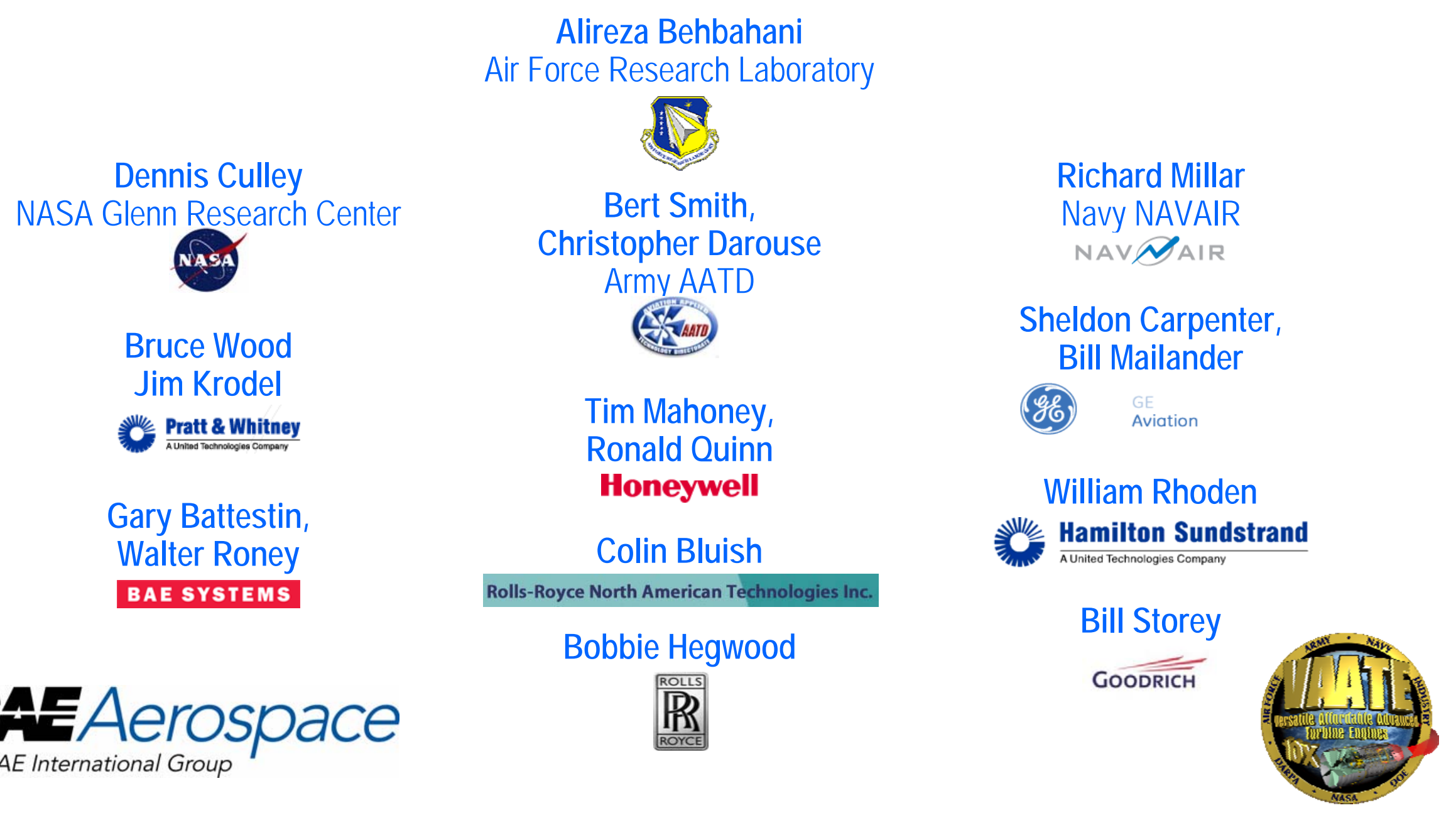




\section{Outline}

- Distributed Engine Control Working Group

- Motivation / Goals

- Vision

- Challenges

- Roadmap

- Conclusion 


\section{Distributed Engine Control Working Group}

Charter

The Distributed Engine Control Working Group

(DECWG) is a forum for the discussion of aeropropulsion systems with a specific emphasis on the future development of engine controls, including both hardware and software, for military and commercial engines. By examining the current and future requirements of propulsion engine systems, the group will lay the foundation for a future distributed engine control architecture based upon open system standards. 


\section{Distributed Engine Control Working Group}

\section{The main goals of the DECWG will be:}

- Identify, quantify and validate benefits from the stakeholder perspective.

- Identify the impact of new control strategies on all facets of the user community; including design, fabrication, assembly, supply chain, and operations.

- Identify regulatory and business barriers which impede the implementation of alternate control philosophies.

- Identify existing and emerging technologies which can be leveraged in the aero-engine control system.

- Identify technology barriers which prevent the implementation of alternate control philosophies and provide guidance to industry for their removal.

- Develop an overall roadmap with which to guide the successful implementation of alternate control philosophies. 


\section{Motivation / Goals}

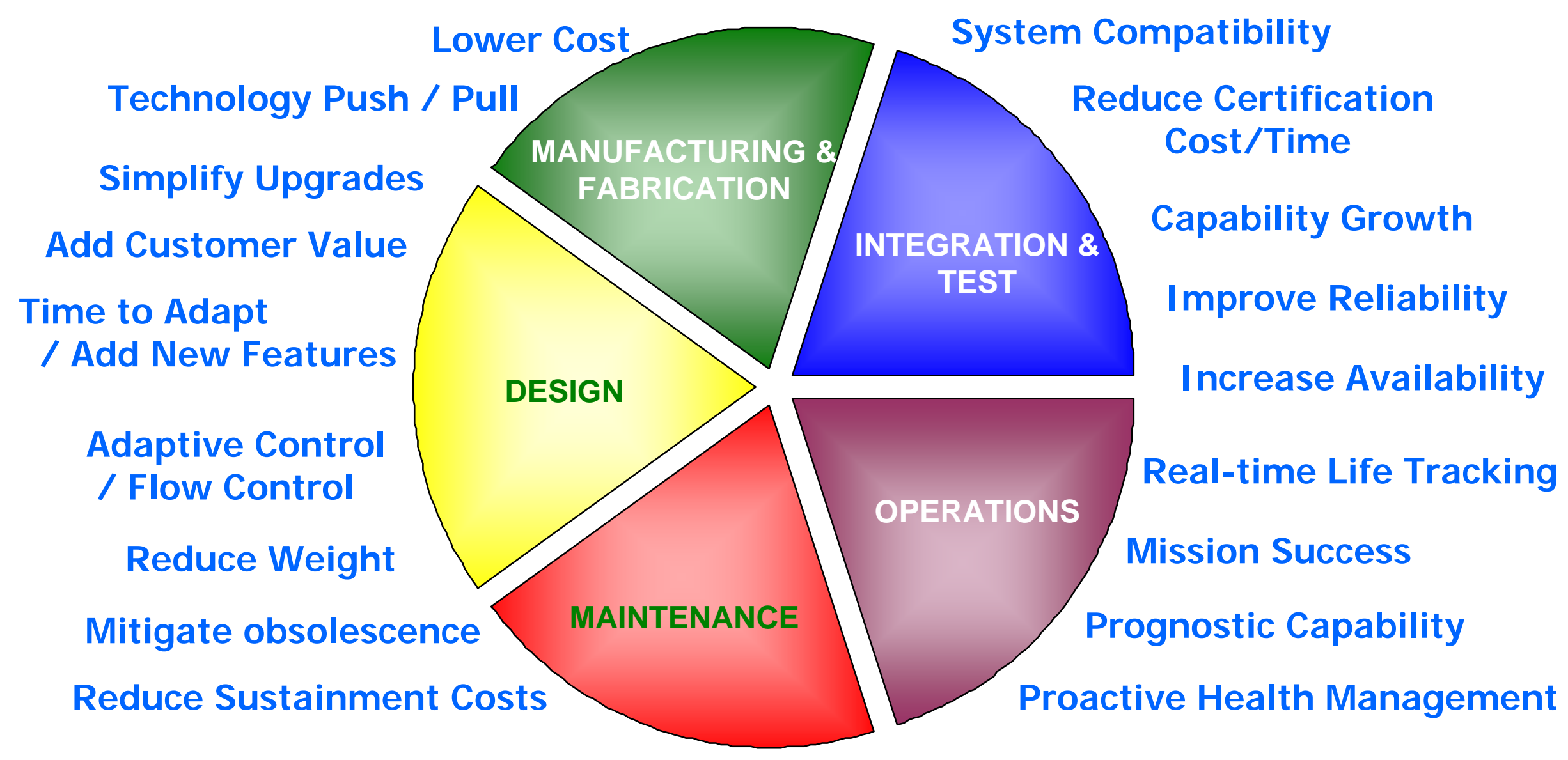

Performance, Time \& Cost 


\section{Central Control System I ssues}

CCS... I nvisible, Static Resources, Centralized Management

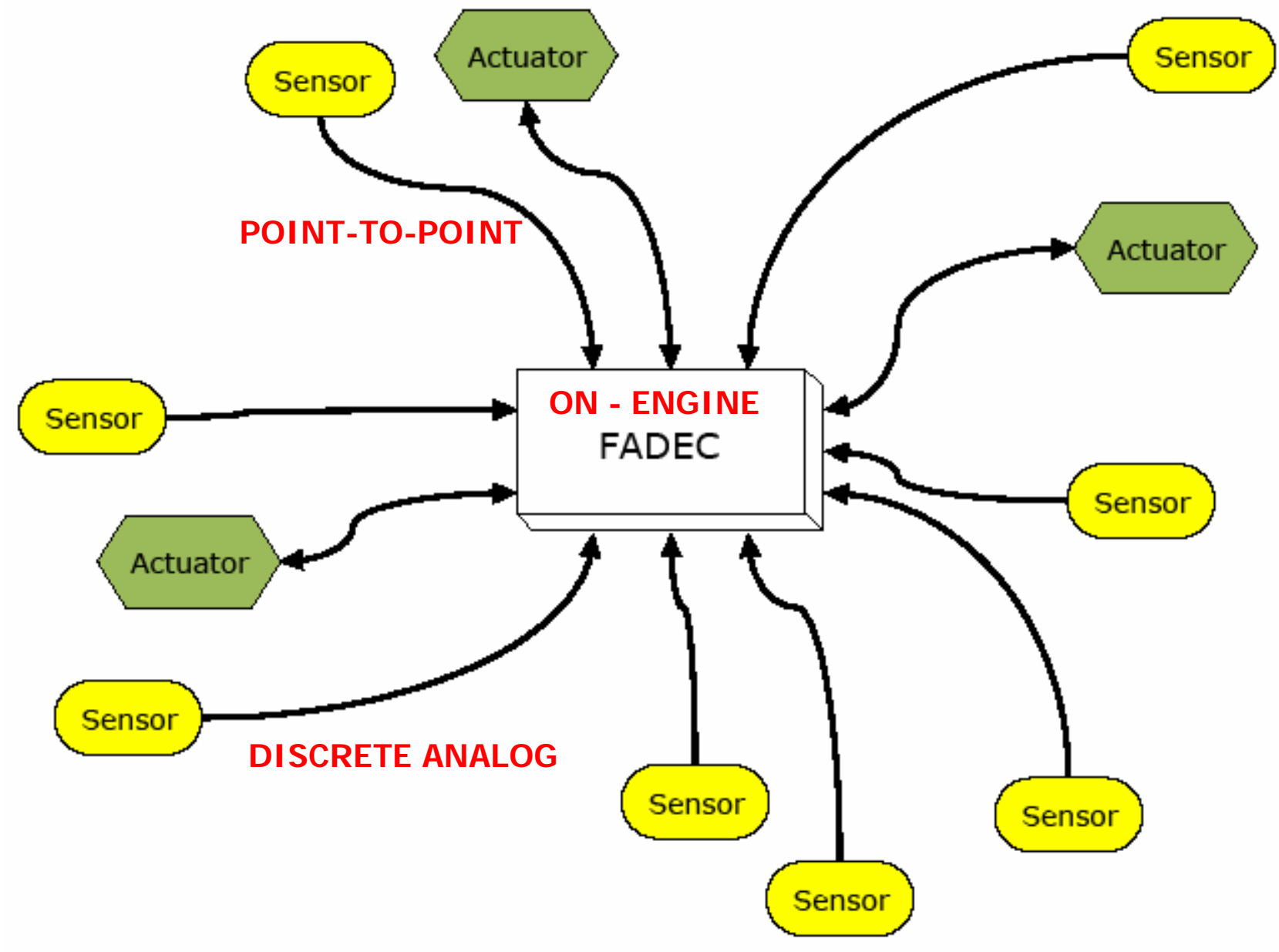

Harness

- Heavy

- Complex

- Reliability I ssue

FADEC

- Hostile Environment

- Expensive

- Prone to Obsolescence

System

- Difficult to I solate Faults

- Difficult to Modify and Upgrade

- How to I mplement Advanced Controls? 


\section{System Design Decisions}

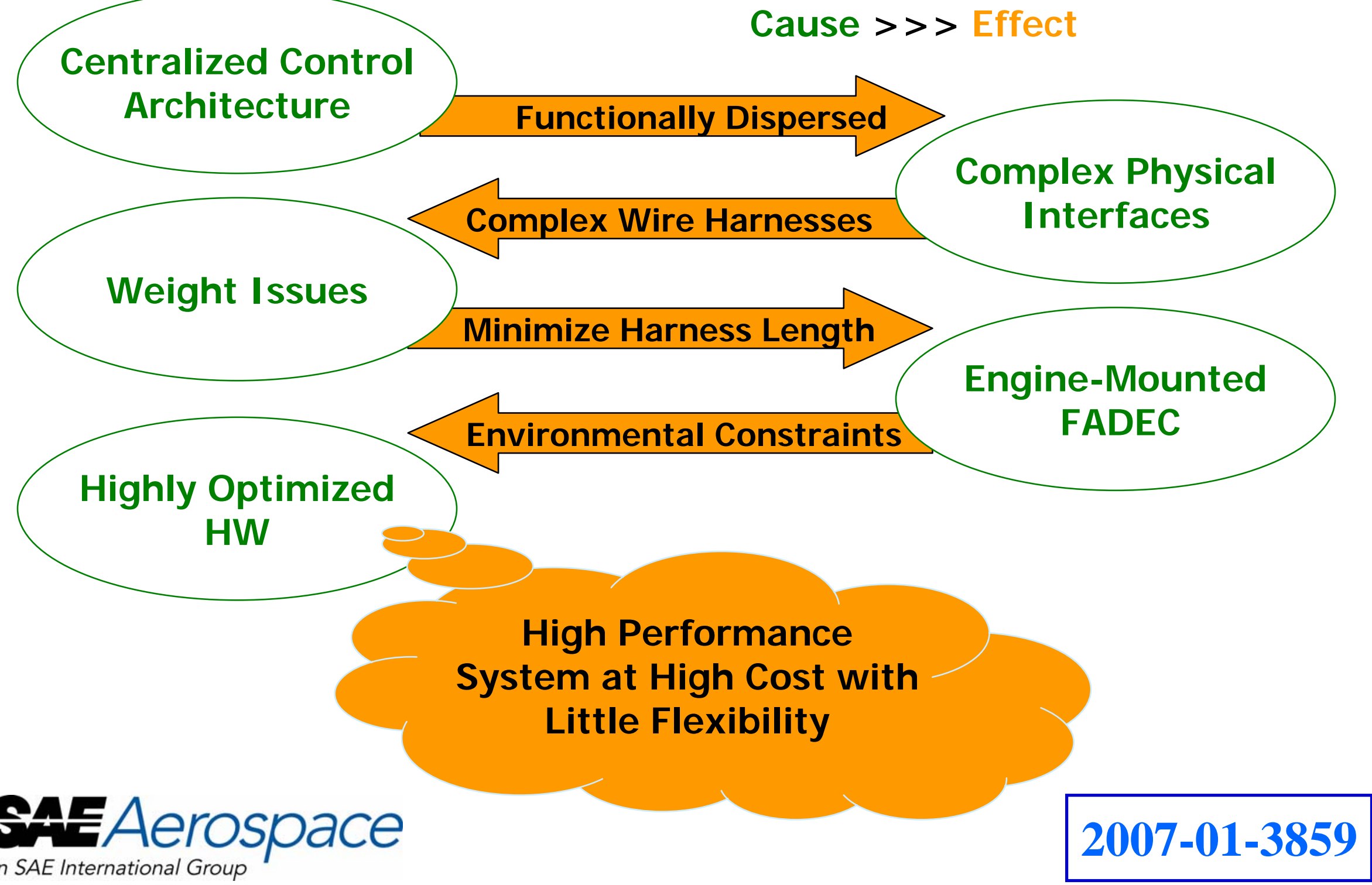




\section{Foundational Development}

- Lightweight Distributed Systems (LDS)

- High Temperature Electronic Components (HiTEC)

- COntrolled Pressure-ratio Engine (COPE) Program

- Propulsion Instrumentation Working Group (PIWG)

- Versatile Affordable Advanced Turbine Engine (VAATE) Initiative

- NASA Glenn Research Center Initiatives

\section{Elements of Distributed Engine Control Technologies have been in development since the early 1990's}




\section{Transition to Distributed Control System}

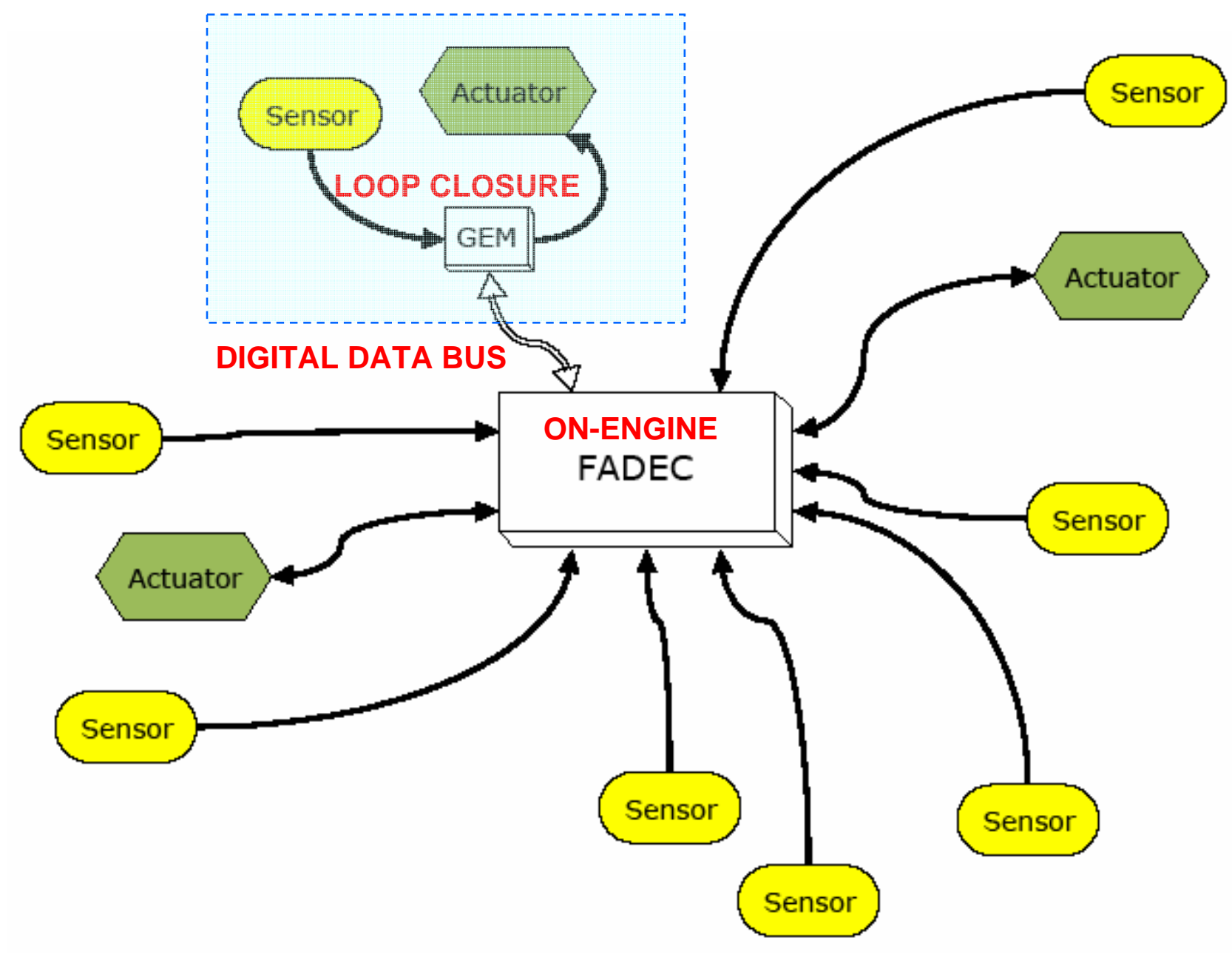

Harness

- Reduced Wire Count

- Simplified Mechanical Interface

FADEC

- Simple Loop Closure OffLoaded to Controller

System

- Limited Fault I solation

- Functional Segregation 


\section{Analysis of Wiring Harness}

Expected I mpact of Distributed Control

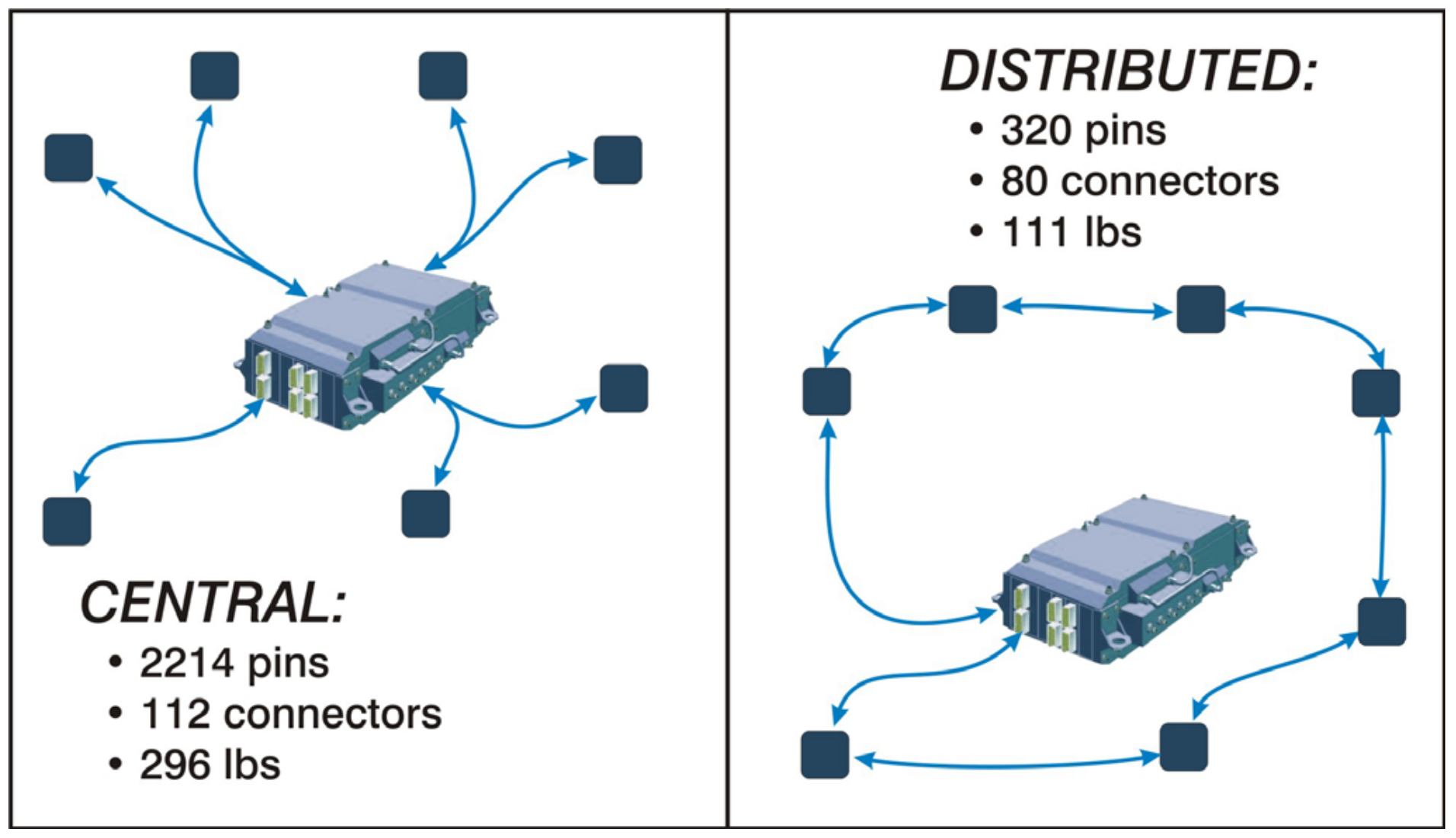




\section{HIGH-TEMPERATURE SMART ACTUATOR KEY COMPONENT FOR DISTRIBUTED CONTROLS}
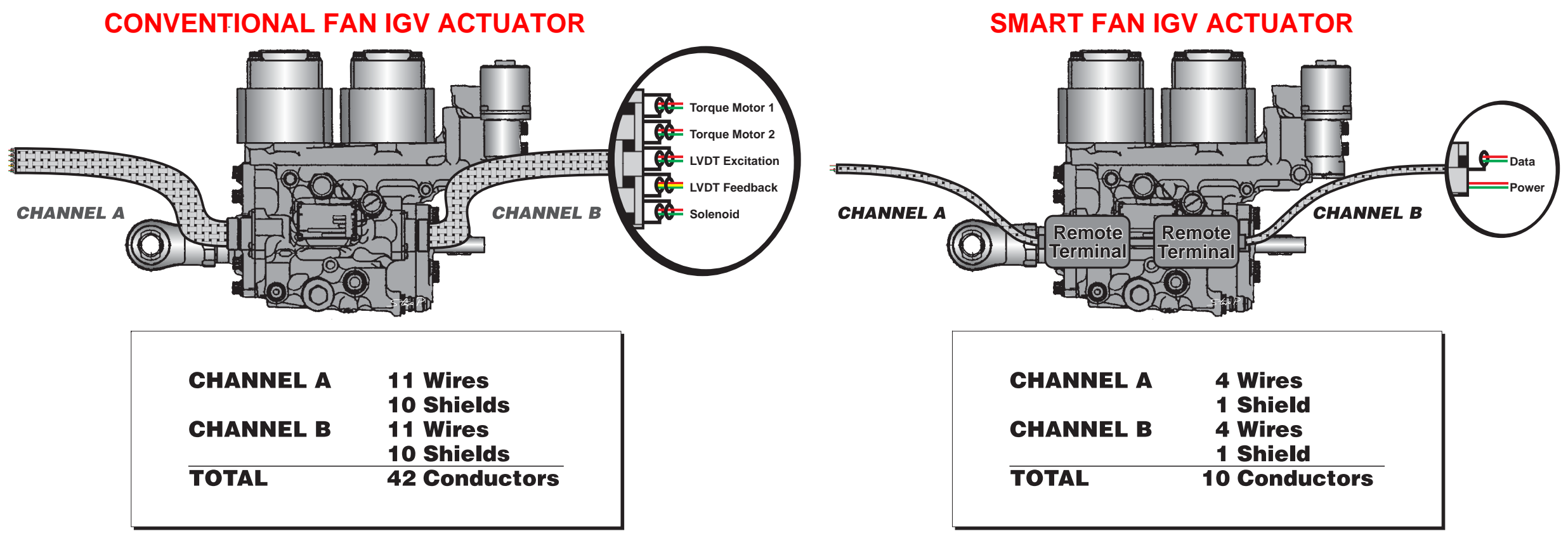

ADDI NG COMPACT ELECTRONI CS MODULE TO ACTUATOR HAS SI GNI FI CANT SYSTEM BENEFITS

- TOTAL WIRE COUNT INTO FADEC REDUCED FROM >500 TO 8

- FADEC COST REDUCTI ON OF \$75K (SUBSTANTI ALLY MORE IF FADEC IS OFF-ENGINE)

- FADEC STANDARDIZATI ON FOR MULTIPLE ENGI NES (NEW FADEC DEVELOPMENT IS \$50M)

- DISTRI BUTED BUILT-IN TEST PROVI DES NEAR 100\% FAULT ISOLATI ON

\section{A4EAerospace}




\section{Vision for Distributed Control}

Decomposition of the Engine Control Problem into FUNCTI ONAL ELEMENTS results in MODULAR components. These components create the building blocks of any engine control system.

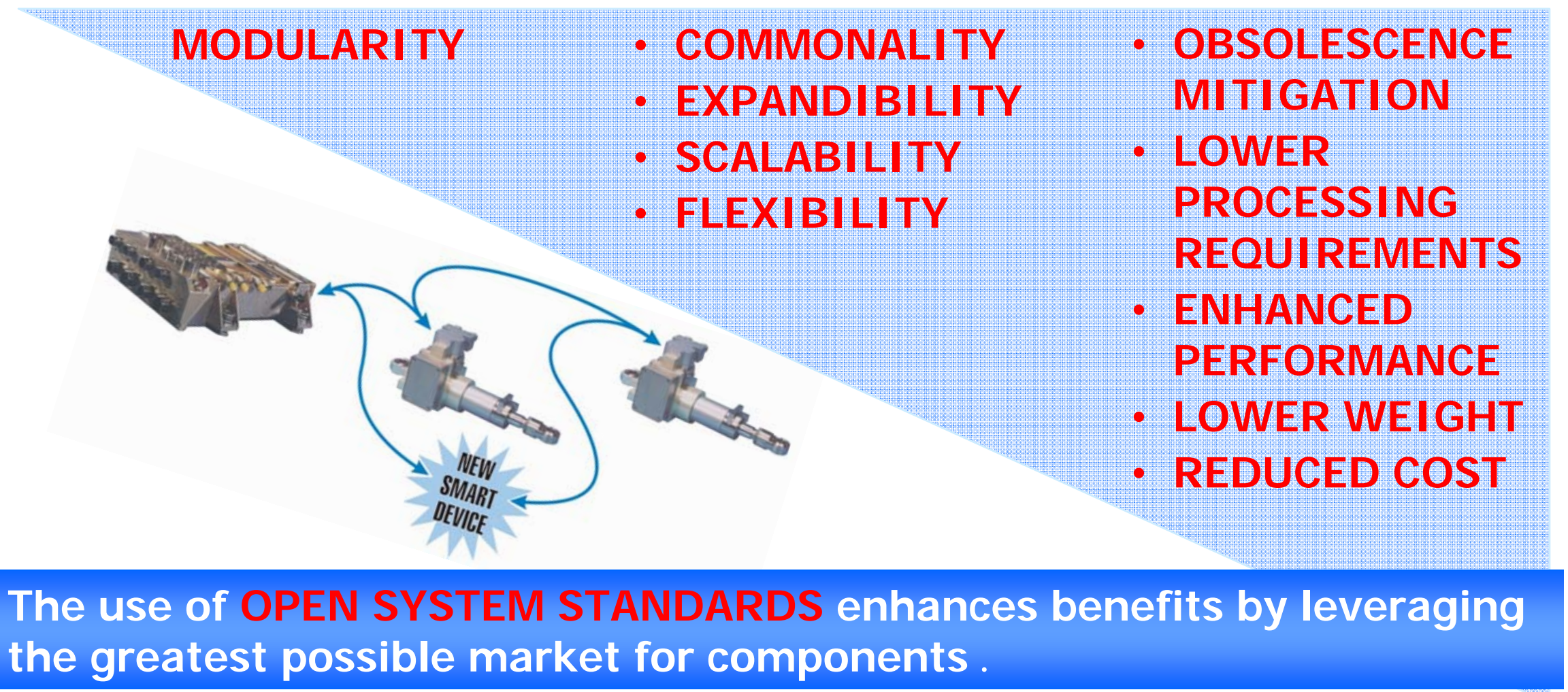




\section{Modular Design Elements for Engine Control}

\section{In Distributed Control much of the Hardware AND Software can be reused in the system AND across engine platforms}

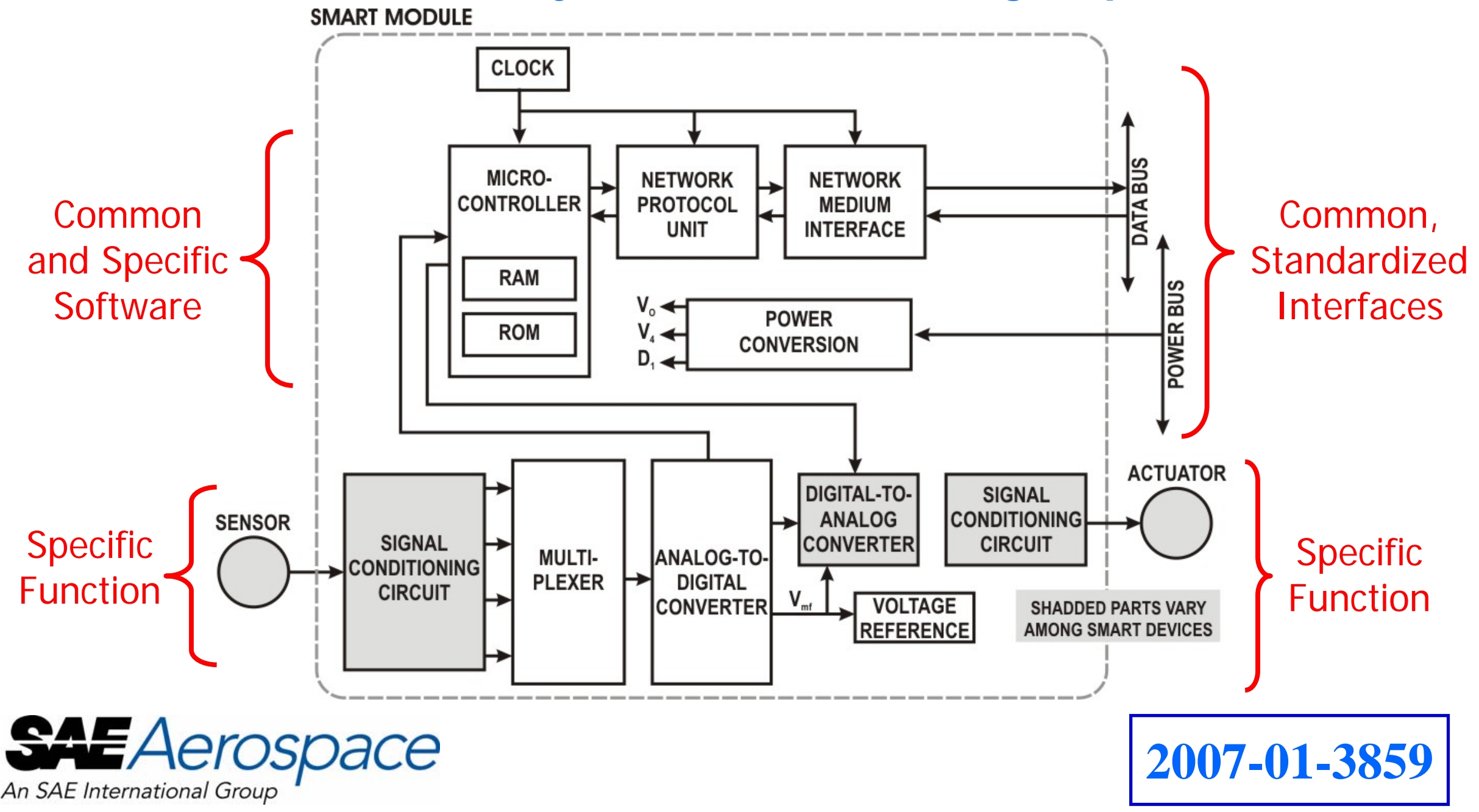




\section{I ntegrated Distributed Engine Control}

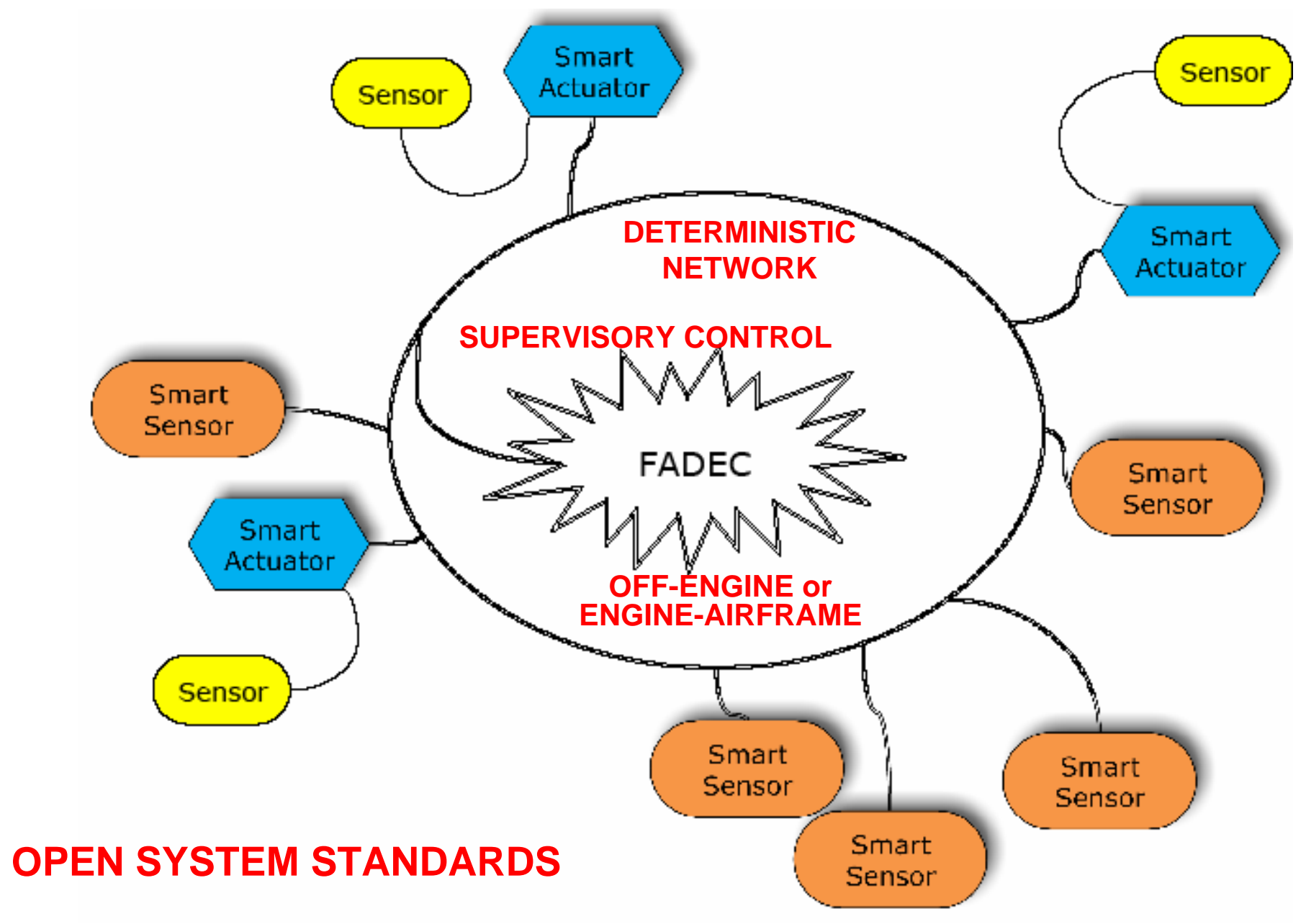




\section{Embedded Distributed Control}

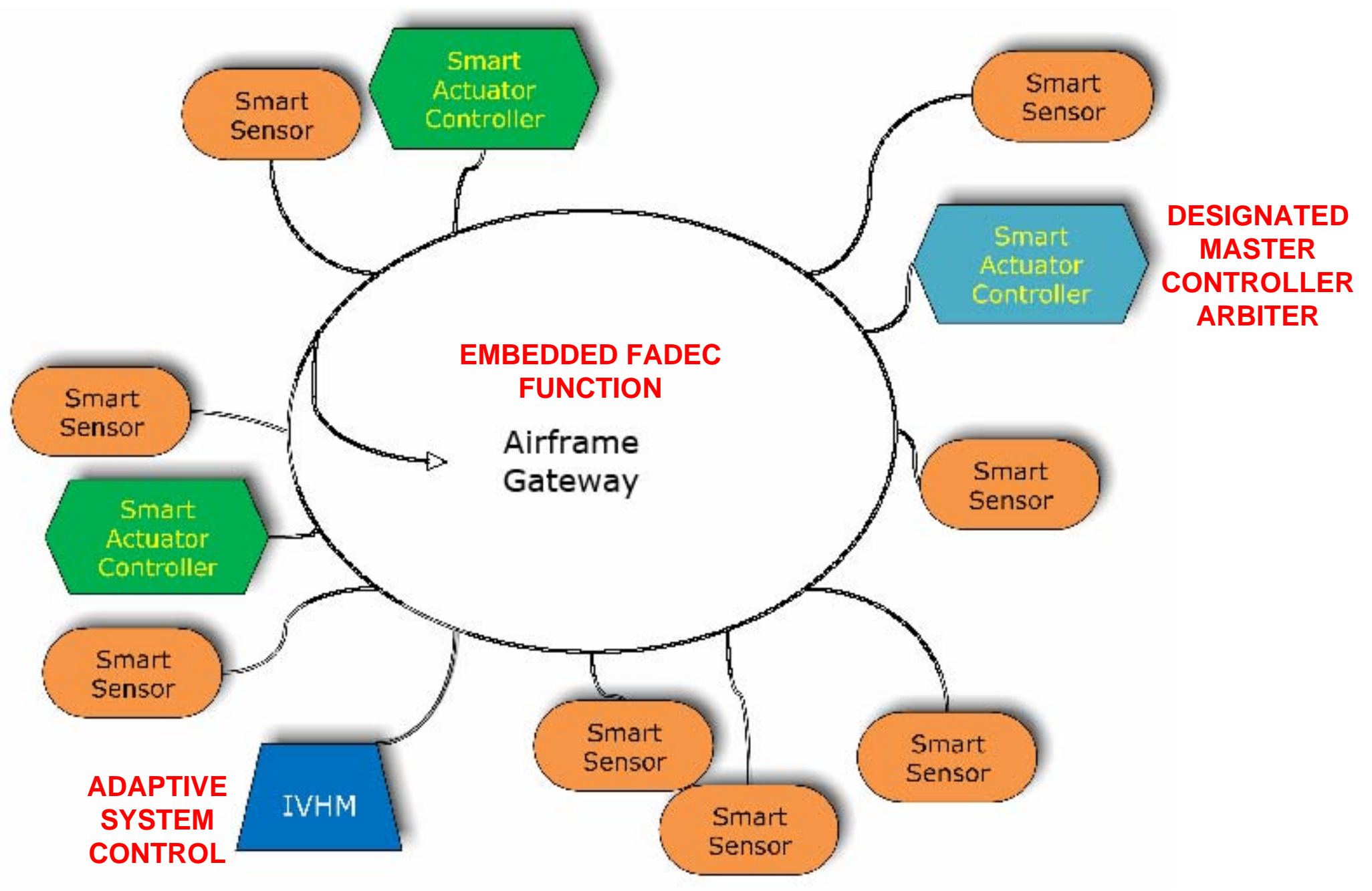




\section{Distributed Architecture Flexibility}

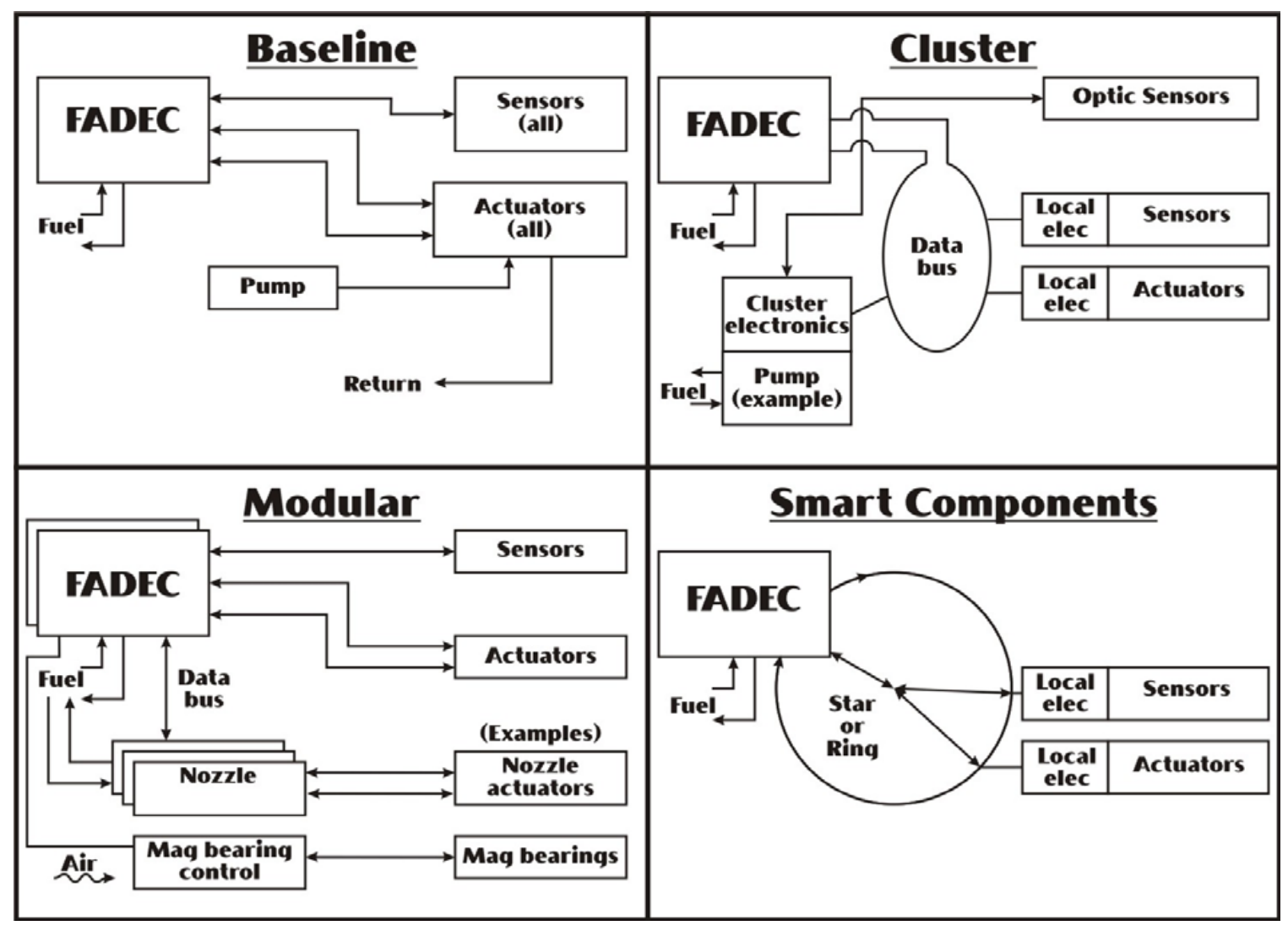

\section{Distributed Architecture Does NOT Force a Specific Configuration It Provides for the Best Choice on a Given Platform}




\section{Challenges}

- Engine Environment and High Temperature Electronics

- Certification / Safety / Regulatory Environment

- Data Bus and Communications

- Functional Partitioning

- Redundancy and Resource Management

- Market Size

- Increased Maintenance Cost

- Distributed Systems Competencies 


\section{Elements of the Development Roadmap}

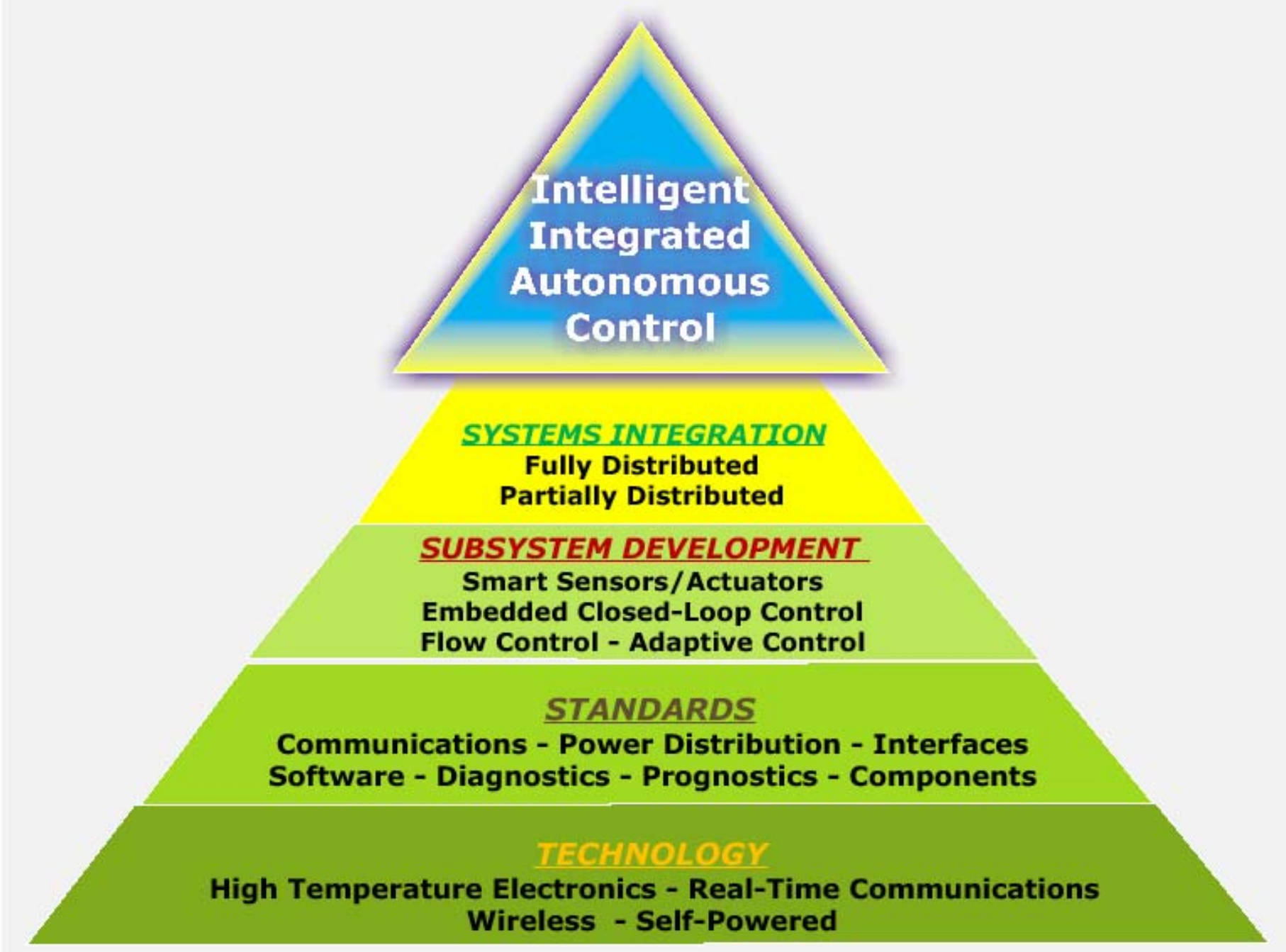




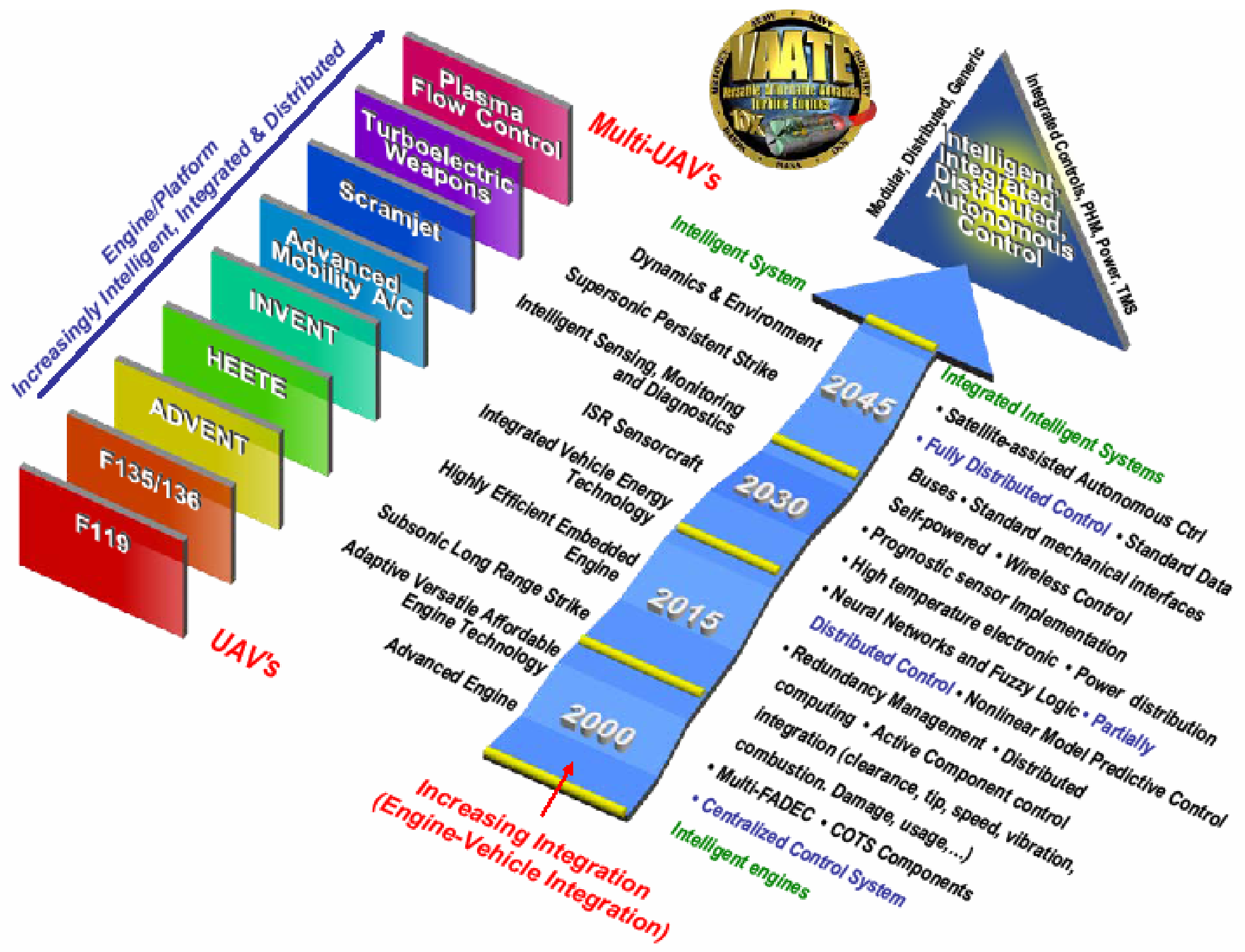




\section{Expectations for Future Engines}

\section{CURRENT ENGI NES:}

- Mechanical / Structural / Aerothermodynamic design provides a fixed optimum operating point

- Large, fixed safety margins accommodate worst case deterioration and operating conditions

- Inflexible engine response to changing operational \& environmental conditions

- Maximum performance compromised for wider operability

- High support costs

\section{FUTURE I NTELLI GENT ENGI NES:}

- Intelligent control maintains optimum engine operation through adaptive response to all changing conditions while maintaining safety margins

- Accommodation for internal (engine health) or external (new/changed missions) conditions

- Performance requirements met through End-of-Life

- Increased knowledge of flowpath and mechanical conditions enable optimization, self-diagnosis, self-prognosis 


\section{I ntegrated System Design Process}

Evolutionary Development Process...

Deploying COTS as much as possible ...

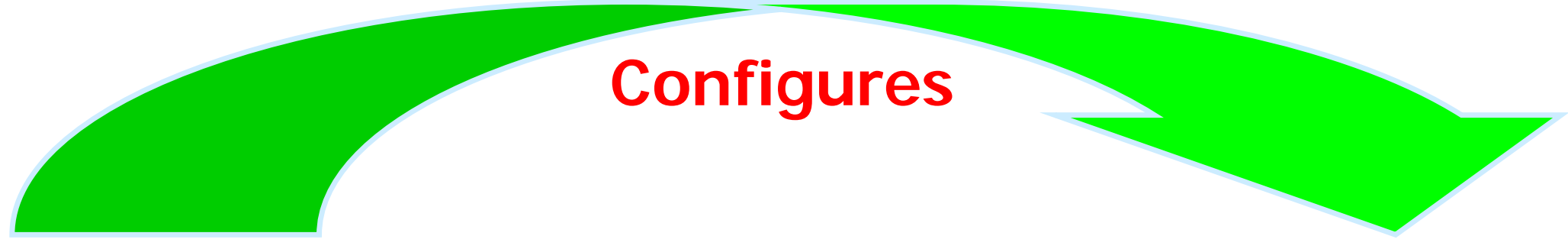

Processes

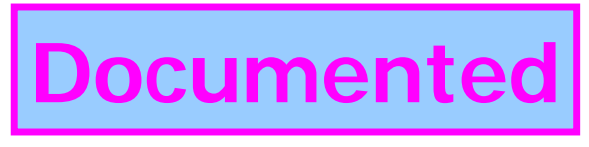

Hardware Software

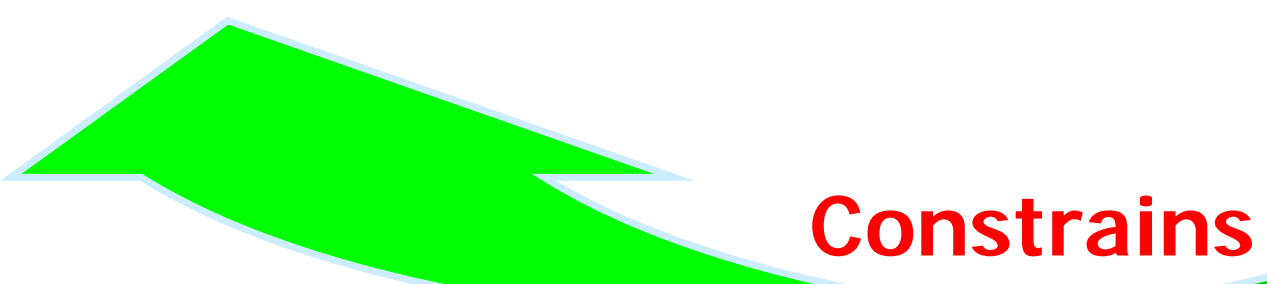

Define and Refine the Process and Configuration Design H/W and S/W simultaneously... 


\section{Conclusion}

- Aero-engine control systems will decide the success of future aeropropulsion systems; Transforming the control system into a distributed architecture, based on open system standards, is necessary to meet the challenge.

- High temperature electronics is the enabling technology for aeroengine distributed control.

- The DECWG perceives the benefits of distributed engine control as:

1. Reducing the size/weight/cost of wiring harnesses

2. Simplification of system upgrades,

3. Distribution of computational burden,

4. Increased robustness against faults/damage

5. Mitigation obsolescence issues. 